\title{
THE EFFECT OF METAL LOADING ON THE PERFORMANCE OF TRI- METALLIC SUPPORTED CATALYST FOR CARBON NANOTUBES SYNTHESIS FROM LIQUEFIED PETROLEUM GAS
}

\author{
Puguh Setyopratomo $^{1}$, Praswasti P.D.K. Wulan ${ }^{1^{*}}$, Mahmud Sudibandriyo ${ }^{1}$ \\ ${ }^{1}$ Department of Chemical Engineering, Faculty of Engineering, Universitas Indonesia, Kampus UI \\ Depok, Depok 16424, Indonesia
}

(Received: February 2017 / Revised: October 2017 / Accepted: January 2018)

\begin{abstract}
Carbon nanotubes (CNT) were synthesized from liquefied petroleum gas by a chemical vapor deposition method using a $\mathrm{Fe}-\mathrm{Co}-\mathrm{Mo} / \mathrm{MgO}$ supported catalyst. Metal loading was varied from 2.5 to $20 \mathrm{wt} \%$. The catalyst with metal loading of $10 \mathrm{wt} \%$ produced the highest CNT yield, at $4.55 \mathrm{~g} \mathrm{CNT} / \mathrm{g}$ catalyst. This high CNT yield was attributed to the high pore volume of the catalyst. The diameter of the CNT was quite variable: the outer diameter ranged from about 4 to $12 \mathrm{~nm}$, while the inner diameter ranged from about 2 to $5 \mathrm{~nm}$. The catalyst with $10 \mathrm{wt} \%$ metal loading produced CNT with the highest surface area and the largest total pore volume. XRD analysis detected the existence of highly oriented pyrolytic graphite, $\mathrm{C}(002)$, at 2 theta $\approx 26^{\circ}$, which was attributed to the CNT.
\end{abstract}

Keywords: Carbon nanotubes; Chemical vapor deposition; Liquefied petroleum gas; Metal loading; Supported catalyst

\section{INTRODUCTION}

Various methods are available for carbon nanotube (CNT) synthesis, but chemical vapor deposition (CVD) is viewed as having the most potential for use in large scale production. This is because CVD is easily controlled and less expensive than other CNT synthesis methods, and it can be operated at atmospheric pressure and a lower temperature (i.e., 500-1000 ${ }^{\circ} \mathrm{C}$ ) (Tapasztó et al., 2005).

In CNT production by CVD, the performance of the catalysts is often more efficient if mixtures of transition metals are used, rather than a single metal alone. The reaction temperature also can be lowered for mixtures of two or more metals (Dupuis, 2005). Ago et al. (2006) reported that catalyst activity increased in accordance with the metal used, in the order of $\mathrm{Fe}>\mathrm{Co}>\mathrm{Ni}$. Although Fe is more active than $\mathrm{Co}$, Co is superior to $\mathrm{Fe}$ for producing CNT with respect to the degree of graphitization and the CNT structure (Fonseca et al., 1996; Hernadi et al., 2000).

Molybdenum (Mo) is usually added to the Fe or Co catalyst to increase its activity. Mo does not play a role as an active catalyst; instead, it serves as a promoter or activator to enhance the catalyst performance. Mo also acts as an inhibitor to prevent rapid deactivation of the catalyst (Dupuis, 2005; Ago et al., 2006). Mo also improves dispersion and prevents the sintering of Fe nanoparticles (Zhang et al., 2011). An advantage of using $\mathrm{MgO}$ as a catalyst support is that it increases the CNT yield and it can be separated easily from the CNT product (Tsoufis et al.,

\footnotetext{
${ }^{*}$ Corresponding author's email: wulan@che.ui.ac.id, Tel: +62-21-7863516, Fax: +62-21-7863515 Permalink/DOI: https://dx.doi.org/10.14716/ijtech.v9i1.1165
} 
2007) by a simple acid treatment, thereby facilitating the purification of CNT (Ago et al., 2006).

A significant factor for controlling catalyst performance is the level of metal loading (Tsoufis et al., 2007). The size of metal nanoparticles dispersed on a catalyst support is affected by the level of metal loading, as a lower metal loading results in a smaller size of the metal nanoparticles. By contrast, increased metal loading may result in sintering of the metal particles (Zhang et al., 2011). The metal loading also substantially affects the extent of dispersion of the metal nanoparticles on the support (Wei et al., 2008).

The main disadvantage of using a single metal as an active catalyst component is the low performance, as described above. The aim of the present study was to examine the use of a trimetallic supported catalyst (Fe-Co-Mo/MgO) for CNT synthesis by the CVD method, focusing on the effect of metal loading on the catalyst performance. The main observed parameter of the catalyst performance was CNT yield, which was determined by the mass of CNT produced per unit mass of catalyst. The quality of the CNT produced was also analyzed.

\section{EXPERIMENTAL}

\subsection{Catalyst Preparation}

Tri-metallic Fe-Co-Mo/MgO catalysts with a weight ratio of Fe:Co:Mo= 2:2:1 were prepared with different metal loading. The Mo component was fixed at $20 \mathrm{wt} \%$ of the metallic components, based on previous work that showed a good catalytic performance with approximately $20 \mathrm{wt} \%$ Mo (Liu \& Fang, 2006; Wang et al., 2014). The masses of Fe and Co were set as equal. Five metal loading variations $(2.5,5,10,15$, and $20 \mathrm{wt} \%)$ were tested, giving a prepared catalyst composition, in percent by weight of Fe:Co:Mo:MgO, of (1:1:0.5:97.5), (2:2:1:95), (4:4:2:90), (6:6:3:85), and (8:8:4:80). Solid crystals of ferric (III) nitrate nonahydrate, cobalt (II) nitrate, and ammonium heptamolybdate tetrahydrate (all obtained from Merck Millipore) were used as the metal precursors, whereas the catalyst support was $\mathrm{MgO}$ powder (also from Merck Millipore). A wet impregnation method (Maccalini et al., 2010) was used to deposit the metal components onto the $\mathrm{MgO}$ support. For example, to prepare a catalyst with a weight composition of Fe:Co:Mo:MgO = 4:4:2:90, $18.0000 \mathrm{~g} \mathrm{MgO}$ powder was mixed with $360 \mathrm{ml}$ distilled water, sonicated, and then stirred for 1 hour. Subsequently, a metal precursor solution, which was a mixture of $5.7848 \mathrm{~g} \quad\left(\mathrm{Fe}\left(\mathrm{NO}_{3}\right)_{3} .9 \mathrm{H}_{2} \mathrm{O}\right), \quad 3.9491 \mathrm{~g} \quad\left(\mathrm{Co}\left(\mathrm{NO}_{3}\right)_{2} .6 \mathrm{H}_{2} \mathrm{O}\right), \quad 0.7358 \mathrm{~g}$ $\left(\left(\mathrm{NH}_{4}\right) 6 \mathrm{Mo}_{7} \mathrm{O}_{24} .4 \mathrm{H}_{2} \mathrm{O}\right)$, and $180 \mathrm{ml}$ distilled water, was added to the $\mathrm{MgO}$ slurry, with continued stirring for another 30 minutes. The solution was then dried under vacuum at $110^{\circ} \mathrm{C}$. The obtained solid catalyst was milled and then calcined in an electric furnace at $500^{\circ} \mathrm{C}$ for 4 hours.

\subsection{The Reactor for CNT Synthesis}

The CNT were synthesized in an electrically heated vertical tubular reactor. The reactor arrangement is shown in Figure 1.

The reactor was constructed from a quartz tube $30 \mathrm{~cm}$ in length and $1.6 \mathrm{~cm}$ inner diameter. The reactor was covered with a tubular electrical furnace with a power capacity of $1 \mathrm{~kW}$. The furnace temperature was detected using a thermocouple installed in the middle of the furnace and mounted between the inner surface of the furnace and the outer surface of the tubular reactor. Two bundles of quartz wool were fitted at two sites within the reactor, one (lower quartz wool) served as a gas distributor as well as the catalyst holder, while the other (upper quartz wool), which was fitted in the upper part of the reactor tube, served as a filter to prevent CNT products from being carried out of the reactor in the flow of gas.

\subsection{The Experimental Procedure}

The quartz wool, as well as the catalyst, were introduced into the reactor through the upper end of the reactor by removing the rubber plug. As much as $0.2 \mathrm{~g}$ calcined catalyst was used in each experiment. Prior to performing CNT synthesis, the catalyst was reduced at $450^{\circ} \mathrm{C}$ for 5 hours by 
flowing hydrogen at a flow rate of $90 \mathrm{~cm}^{3} /$ minute.

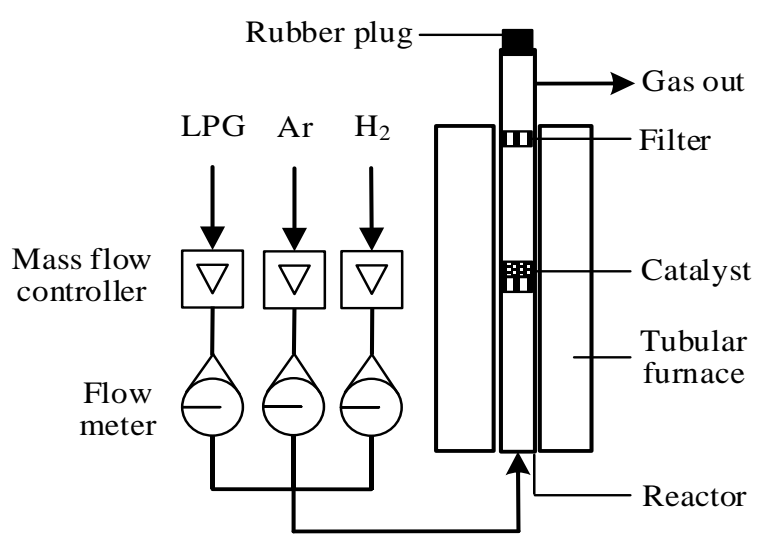

Figure 1 The reactor arrangement

CNT synthesis was then carried out at a reactor temperature of $750-850^{\circ} \mathrm{C}$ for 30 minutes by flowing a mixture of liquefied petroleum gas (LPG), hydrogen, and argon at flow rate 25 $\mathrm{cm}^{3} /$ minute, $19 \mathrm{~cm}^{3} /$ minute, and $150 \mathrm{~cm}^{3} /$ minute, respectively. At the end of synthesis, all the gas flows were switched off, as well as the furnace heater, to allow the reactor to cool to room temperature. The mass of CNT was calculated from the reactor weight difference before and after synthesis. The CNT product was stored in dark glass bottles for analysis.

\subsection{Analysis and Characterization Techniques}

The existence of a crystalline phase in the calcined catalyst, as well as in the as-grown CNT, was investigated using an X-ray diffractometer (Shimadzu 7000 Maxima-X). The CNT orientation and morphology was analyzed using a transmission electron microscope (TEM; JEOL JEM 1400). A surface area analyzer (Quantachrome Nova 2000 Series - NovaWin Instruments version 11.03) was used to analyze the surface areas and pore characteristics of the catalyst and the CNT.

\section{RESULTS AND DISCUSSION}

\subsection{The CNT Yield}

In this work, the CNT yield was expressed in two ways. The first way was to express the yield as the mass of CNT per mass of calcined catalyst feed. The second way was to express the yield as the mass of CNT per mass of the active components, where the mass of CNT was the difference between the mass of the as-grown CNT and the mass of the fresh catalyst fed. In the case, the mass of CNT also included the mass of amorphous carbon formed during the synthesis. The mass of active components was the total mass of $\mathrm{Fe}$ and $\mathrm{Co}$ in the catalyst. The Mo component was not counted as an active component as Mo has no activity in the formation and growth of the CNT. The yield of CNT at all metal loadings is presented in Figure 2. The highest yield was obtained at a metal loading of $10 \mathrm{wt} \%$, which is $4.55 \mathrm{~g} \mathrm{CNT} / \mathrm{g}$ catalyst and is equivalent to 68.98 g CNT/g active components. This result was comparable with the yield obtained from CVD synthesis using the same carbon source conducted by Huang et al. (2008), who obtained $8 \mathrm{~g}$ $\mathrm{CNT} / \mathrm{g}$ catalyst using a ferrocene catalyst but at a longer reaction time (60 minutes).

The CNT yield may have a relationship with the pore volume of the catalyst, as indicated in Figure 3. The largest pore volume for the calcined catalyst was obtained when the metal loading was $10 \mathrm{wt} \%$, which is $0.632 \mathrm{~cm}^{3} / \mathrm{g}$. A large pore volume will be beneficial because it will increase the loading capacity and minimize barriers to diffusion and transport. A large pore volume for a catalyst allows the reactant molecules to diffuse deep into the interior of the catalyst because of the low barriers and reduced tendency for plugging (Xu et al., 2016). 


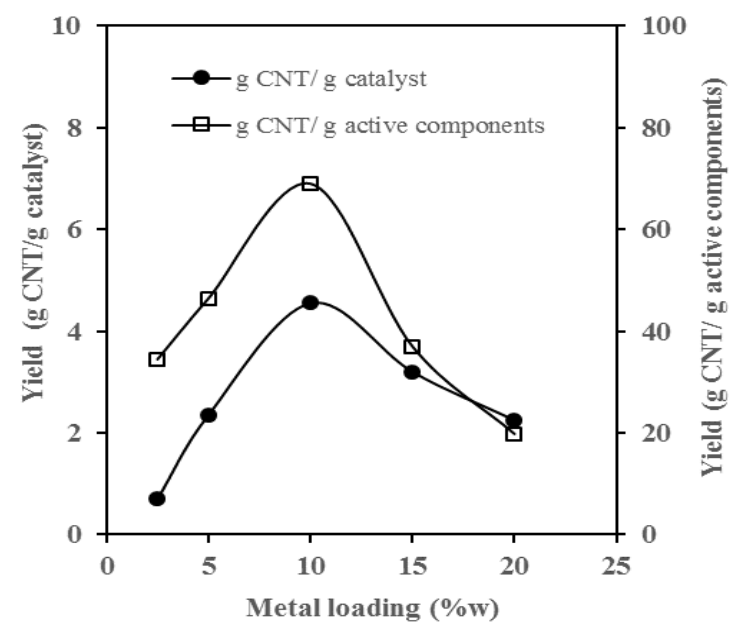

Figure 2 Carbon nanotube yields at all metal loadings

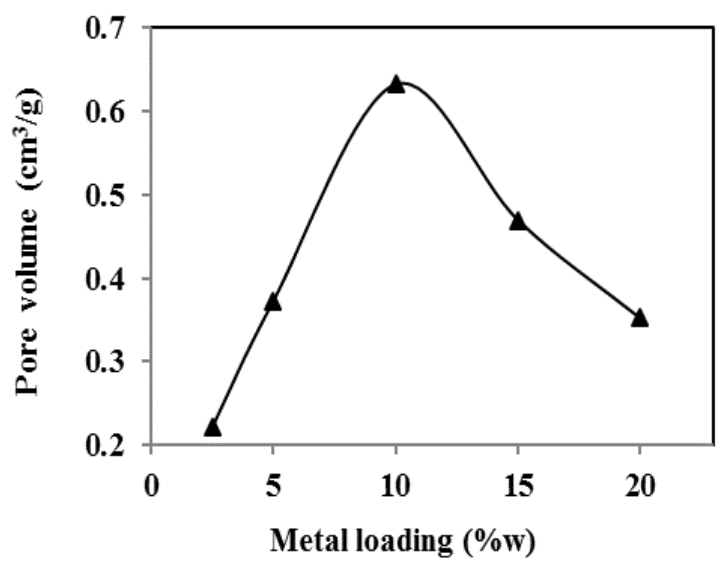

Figure 3 Pore volume of the calcined catalyst

The observed influence of the pore volume in the reaction system, as described above, led to the consideration that the high CNT yield achieved at a metal loading of $10 \mathrm{wt} \%$ could be attributed to the high pore volume of the catalyst. Increases in the metal loading resulted in a decrease in the CNT yield. The large amount of metal components that was deposited on the support led to the partial closure of the pore openings in the support, thereby ultimately reducing the pore volume accessible to the reactant. The yield curve also had an identical profile to the pore volume curve. Both curves had a parabolic shape and showed a peak when the metal loading was $10 \mathrm{wt} \%$. Thus, the pore volume of the catalyst was confirmed to play an important role in the synthesis of CNT by the CVD method. The high pore volume of the catalyst is believed to be formed primarily by the deposition of metal components onto the surface of the catalyst, because the analysis of $\mathrm{MgO}$ powder gives a total pore volume of only $0.19 \mathrm{~cm}^{3} / \mathrm{g}$.

The CNT growth mechanism is based on the vapor-liquid-solid model (Ago et al., 2006). The high yield of CNT obtained at a metal loading of $10 \mathrm{wt} \%$ shows that, at that level of metal loading, the combination of $\mathrm{Fe}, \mathrm{Co}$, and Mo metal components on the $\mathrm{MgO}$ support has good synergism. The combination of $\mathrm{Fe}$ and $\mathrm{Co}$ components gives high activity for decomposing hydrocarbons in the feed, and this combination is capable of forming carbide compounds and facilitates carbon diffusion for CNT growth. The Mo component acts as a good promoter that encourages an increase in CNT yield and prevents the rapid deactivation of the catalyst.

\subsection{The CNT Orientation and Morphology}

The TEM analysis was performed on CNT that were synthesized with a $10 \mathrm{wt} \%$ metal loading catalyst, as that loading had provided the highest CNT yield. The CNT structures are shown in Figure 4.

The CNT were randomly oriented and entangled with one another. Several similar studies also reported a similar orientation (Reyhani et al., 2007; Hordy et al., 2013).

The TEM images show that some of the CNT were a concentric type, and many of them were twisted together. Some areas also showed solid black spots attached to the CNT wall. These spots are considered to be amorphous carbon formed during CNT synthesis. 

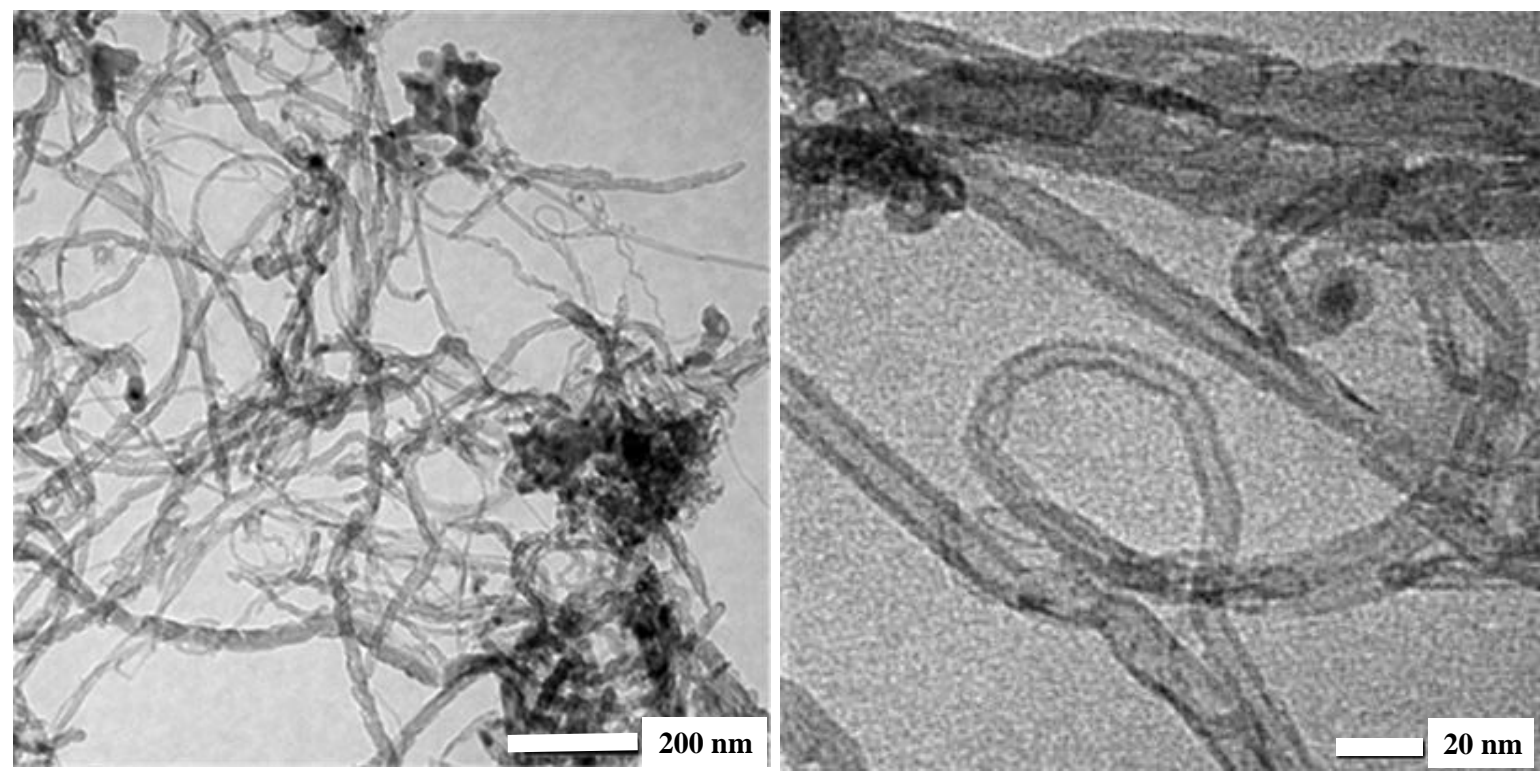

Figure 4 TEM image of CNT synthesized using a $10 \mathrm{wt} \%$ metal loading catalyst

Direct observation of the TEM images revealed a quite variable diameter for the CNT. Manual measurements performed on the TEM images revealed a typical range of about 4 to $12 \mathrm{~nm}$ for the outer diameter, while the inner diameter ranged from about 2 to $5 \mathrm{~nm}$. These measurements confirmed that most of the CNT formed by this synthesis are multi-walled. Taking the value of the graphene sheet thickness as the interlayer distance of the CNT, the CNT consisted of 4-9 layers of graphene sheets.

\subsection{Surface Area and Pore Structure of the CNT}

The surface area and porosity of carbon material attract particular attention due to their major role in many carbonaceous material applications. For instance, in the field of adsorption, the presence of both micropores (pore size $<2 \mathrm{~nm}$ ) and mesopores (pore size 2-50 nm) is crucial because the two pore types facilitate the effective adsorption of molecules with a wide range of molecular sizes (Wang et al., 2006).

Physical adsorption of nitrogen was used to determine the pore characteristics of the CNT. The isotherm obtained from these adsorption/desorption measurements provides information on the surface area and pore structure. The Brunauer-Emmett-Teller (BET) multipoint method was used for the determination of the surface area. The total pore volume was determined from the amount of nitrogen vapor adsorbed at a pressure $(\mathrm{P})$ close to the nitrogen saturation pressure $(\mathrm{Po})$, by assuming that the pores are then filled with liquid nitrogen. The Horvath-Kawazoe (HK) method, which applies a model for slit-shaped pores, was used to determine the pore size distribution of micropores from the low relative pressure ( $\mathrm{P} / \mathrm{Po})$ region of the adsorption isotherm. The BarretJoyner-Halenda $(\mathrm{BJH})$ method was used to determine pore size distribution of the mesopores. The BJH method is based on the Kelvin equation and is corrected for multilayer adsorption. It applies only to pores of the mesopore and small macropore size range (Groen et al., 2003). The BET surface area of the CNT produced at all metal loadings is presented in Figure 5.

The lowest surface area of the CNT was $88 \mathrm{~m}^{2} / \mathrm{g} \mathrm{CNT}$, obtained with the $2.5 \mathrm{wt} \%$ metal loading catalyst, and the highest surface area was $229 \mathrm{~m}^{2} / \mathrm{g}$, obtained with the $10 \mathrm{wt} \%$ metal loading catalyst. For comparison, CVD using methane as the carbon source produced multi-walled CNT with a surface area of $82 \mathrm{~m}^{2} / \mathrm{g}$ (Kuo et al., 2008), whereas multi-walled CNT with a surface area of $187 \mathrm{~m}^{2} / \mathrm{g}$ were reported by Gangupomu et al. (2016). As-grown multi-walled CNT with a wide range surface area, from 50 to $150 \mathrm{~m}^{2} / \mathrm{g}$, have also been reported (Lee \& Park, 2012). 
Other results of surface area and pore characteristic analysis of the CNT are presented in the following figures: the total pore volume (Figure 6), the cumulative micropore volume distribution (Figure 7), and the cumulative BJH pore volume distribution (Figure 8).

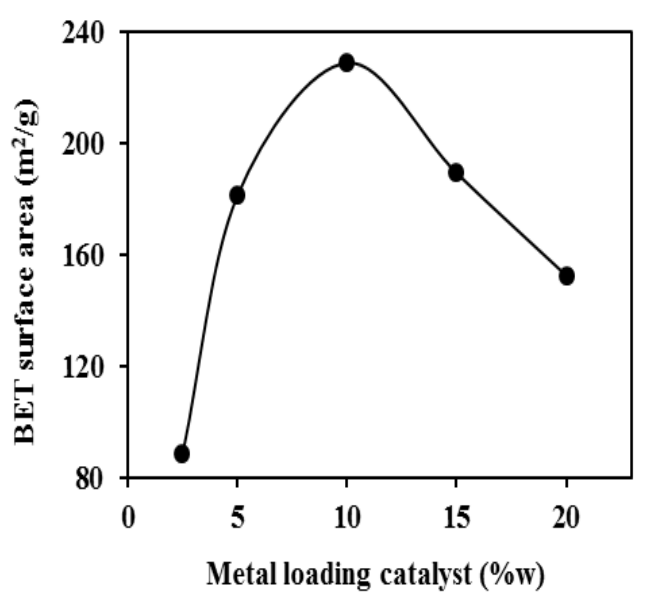

Figure 5 BET surface area of the CNT product at all catalyst metal loadings

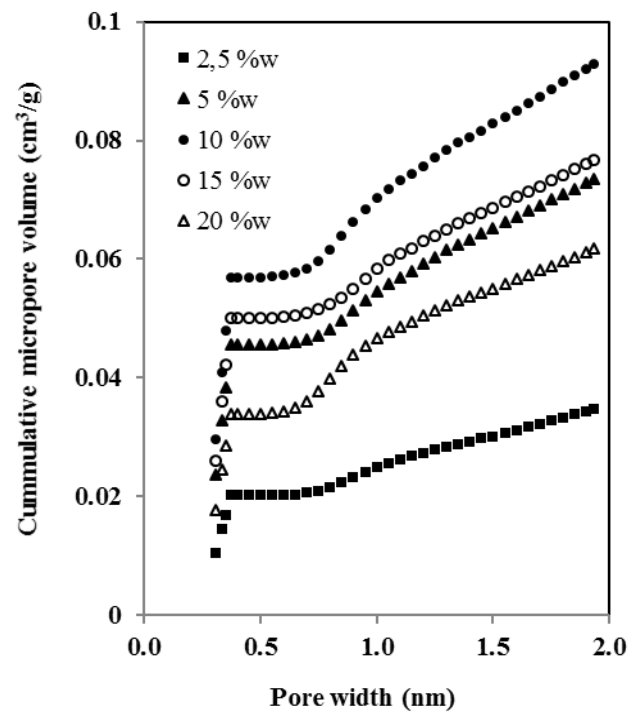

Figure 7 Cumulative micropore volume distribution of the CNT product at all catalyst metal loadings

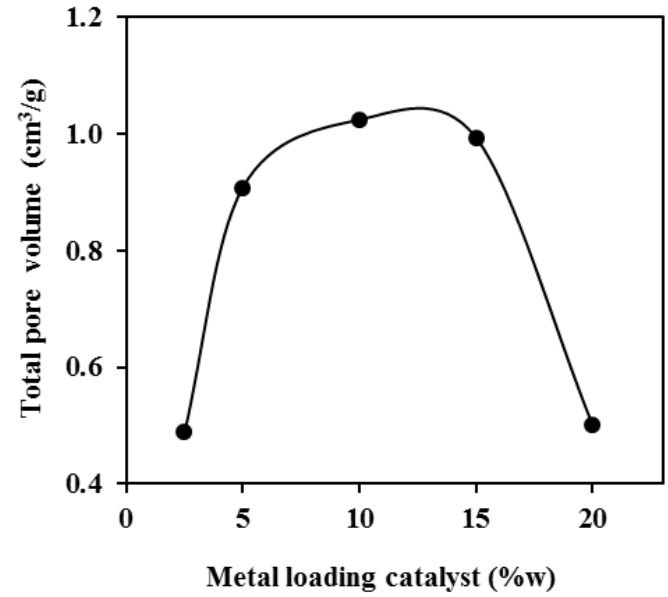

Figure 6 Total pore volume of the CNT product at all catalyst metal loadings

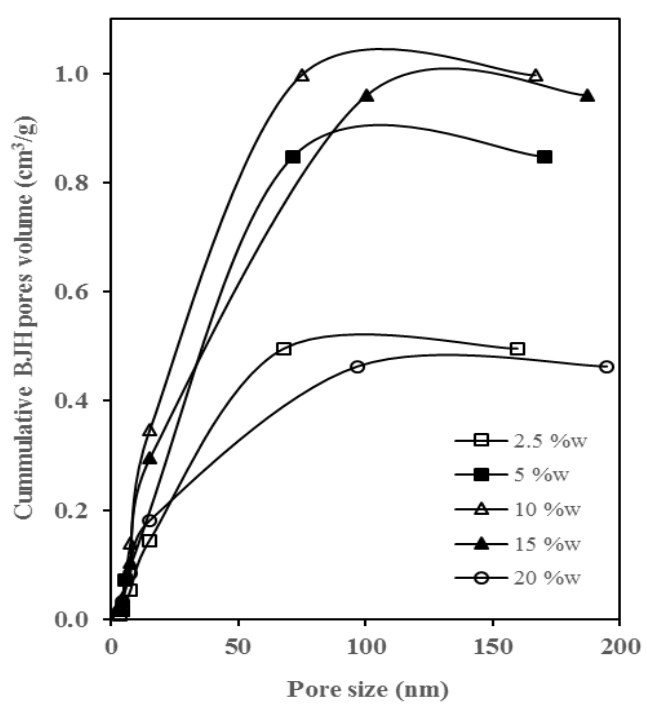

Figure 8 Cumulative BJH pore volume distribution of the CNT product at all catalyst metal loadings

The total pore volume profile of the CNT demonstrated a parabolic shape when plotted against the metal loading, and the highest pore volume of $1.024 \mathrm{~cm}^{3} / \mathrm{g}$ was obtained for the $10 \mathrm{wt} \%$ metal loading catalyst.

The profile for the cumulative micropore volume distribution of the CNT product suggests that micropores with a pore width range around $0.3-0.4 \mathrm{~nm}$ make the largest contribution to the micropore volume. Pores with a pore width less than $0.4 \mathrm{~nm}$ account for approximately $60 \%$ of the total micropore volume.

The cumulative BJH pore volume distribution profile shows that the pore structure of the CNT products was dominated by mesopores, since the profiles tended to be flat at a pore size larger 
than $50 \mathrm{~nm}$. The maximum cumulative $\mathrm{BJH}$ pore volume values, which were close to the values of the total pore volume, also confirmed this fact.

\subsection{XRD Analysis}

The XRD analysis was carried out under the following operating conditions: (i) X-ray tube, target: $\mathrm{Cu}$; voltage: $40.0(\mathrm{kV})$; current: $30.0(\mathrm{~mA})$; (ii) Slits, divergence slit: 1.00000 (deg); scatter slit: 1.00000 (deg); receiving slit: $0.30000(\mathrm{~mm})$; (iii) Scanning, drive axis: theta-2theta; scan range: 10.0000-80.0000 (deg); scan mode: continuous scan; scan speed: 2.0000 (deg/min); sampling pitch: 0.0200 (deg); preset time: 0.60 (sec).

The XRD patterns of the calcined catalyst were compared for all metal loadings to determine the existence of their crystalline phase, as presented in Figure 9. The peaks due to $\mathrm{MgO}$ were observed at 2 theta, around $36.81^{\circ}, 42.83^{\circ}, 62.20^{\circ}, 74.51^{\circ}$, and $78.47^{\circ}$. These five peaks attributed to $\mathrm{MgO}$ were also detected in the XRD pattern of the reduced $\mathrm{Fe}-\mathrm{Mo} / \mathrm{MgO}$ catalyst in a study conducted by Ni et al. (2009) and in the XRD pattern for the calcined as well as reduced Co$\mathrm{Mo} / \mathrm{MgO}$ catalyst, also reported earlier by $\mathrm{Ni}$ et al. (2006). The patterns also demonstrated that the intensity of the $\mathrm{MgO}$ peaks decreased as the metal loading increased. This reduced peak intensity was attributed to the decreasing mass fraction of the $\mathrm{MgO}$ in the catalyst particles. $\mathrm{FeO}$ and $\mathrm{CoO}$ crystalline phases with very weak intensity were detected at 2 theta around $36.81^{\circ}$, $42.83^{\circ}$, and $62.20^{\circ}$, which also supported the occurrence of the $\mathrm{MgO}$ phase. This weak peak fuses into the $\mathrm{MgO}$ peaks, so it is not clearly visible. The existence of the Mo component was not observed in the XRD patterns. This could have arisen because the Mo oxide was present in an amorphous form or in very small amounts that could not be detected by XRD, as previously reported by Awadallah et al. (2013).

The XRD analysis of the as-grown CNT synthesized using $10 \mathrm{wt} \%$ metal loading catalyst was performed to investigate the crystalline phase after the as-prepared catalyst was subjected to CVD synthesis. The XRD pattern is presented in Figure 10. The characteristic features of a highly oriented pyrolytic graphite (HOPG) were detected at 2 theta $\approx 25.74^{\circ}$. A similar finding was also reported previously (Tsoufis et al., 2007; Hsieh et al., 2009; Maccallini et al., 2010).

The XRD pattern provided strong evidence for the existence of crystalline CNT, since the diffraction peak is close to that of graphite. Furthermore, the presence of the peak is usually attributed to the existence of multi-walled CNT (Maccallini et al., 2010). Using Bragg's equation, Hsieh et al. (2009) calculated the interlayer distance of the CNT (002) peak and found an average value of $0.339-0.341 \mathrm{~nm}$, which was very close to that of highly oriented pyrolytic graphite $(0.335 \mathrm{~nm})$. The XRD pattern of their CNT product also indicated the existence of a graphitic structure of CNT $(100)$ with a lower intensity at 2 theta $\approx 44.58^{\circ}$, which was also detected in the work done by Hsieh et al. (2009).

Again, this result underscores the finding that, at $10 \mathrm{wt} \%$ metal loading, the $\mathrm{Fe}-\mathrm{Co}-\mathrm{Mo} / \mathrm{MgO}$ catalyst successfully facilitated the formation and growth of multi-walled CNT with an ordered structure with a high graphitization degree, in high yield and with excellent surface and pore properties. Of all of the metal loading levels, the catalyst with $10 \mathrm{wt} \%$ metal loading showed the best performance.

Crystalline phases for $\mathrm{MgO}, \mathrm{FeO}$, and $\mathrm{CoO}$ were also observed in the XRD pattern of the asgrown CNT at similar peaks location indicated on the XRD pattern of the calcined catalyst. These peaks were attributed to the presence of the rest of the catalysts, which were still mixed in with the CNT product. 


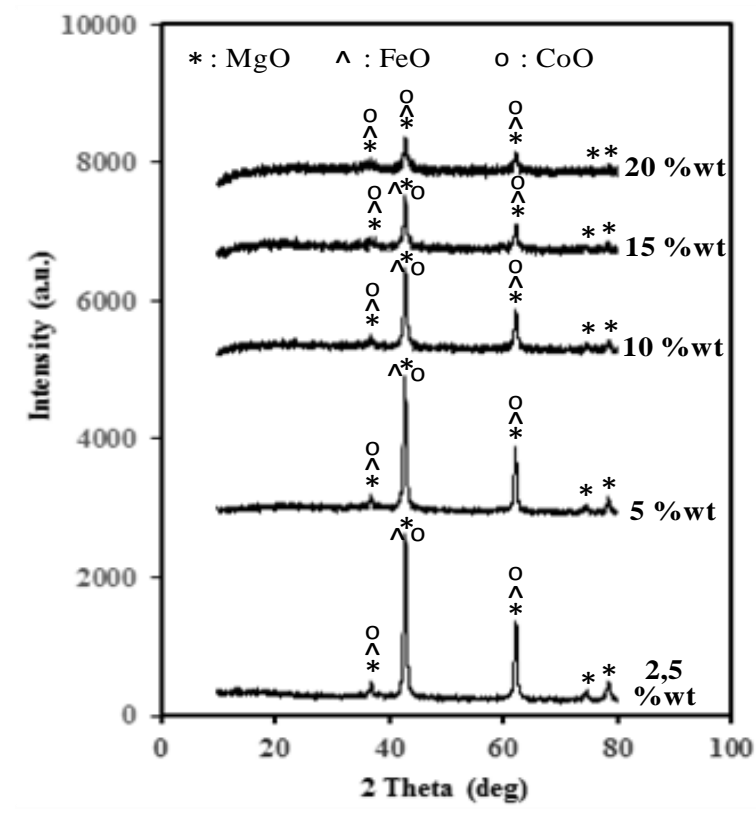

Figure 9 XRD pattern of the calcined catalyst at all catalyst metal loadings

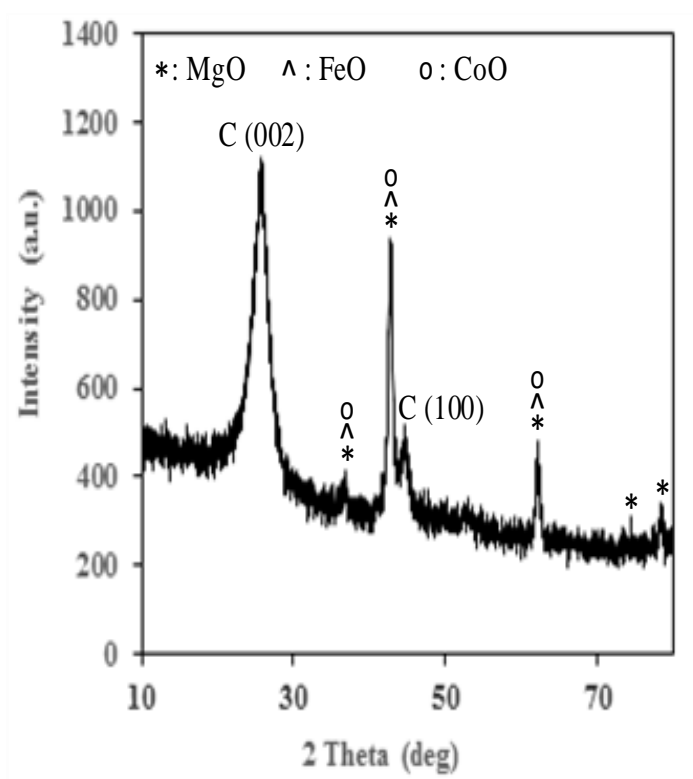

Figure 10 XRD pattern of the CNT synthesized with a catalyst at a $10 \mathrm{wt} \%$ metal loading

\section{CONCLUSION}

We observed a significant influence of the catalyst composition and characteristics on the yield and properties of the produced CNT. The experimental results showed that the high CNT yield was attributed to the high pore volume of the catalyst. This confirmed that the pore volume of the catalyst plays an important role in the growth of CNT. Mesopores dominated the pore distribution of the CNT product. A high yield of CNT with high surface area and pore volume was produced with a $10 \mathrm{wt} \%$ metal loading. The Fe-Co-Mo/MgO catalyst successfully facilitated the formation and growth of multi-walled CNT with ordered structures and a high degree of graphitization.

\section{ACKNOWLEDGEMENT}

The authors wish to thank The Directorate Research and Community Services, Universitas Indonesia, for providing the financial support through The Research Cluster Grant 2015- contract number: 1875/UN2.R12/HKP.05.00/2015.

\section{REFERENCES}

Ago, H., Uehara, N., Yoshihara, N., Tsuji, M., Yumura, M., Tomonaga, N., Setoguchi, T., 2006. Gas Analysis of the CVD Process for High Yield Growth of Carbon Nanotubes over Metalsupported Catalysts. Carbon, Volume 44(14), pp. 2912-2918

Awadallah, A.E., Gad, F.K., Aboul-Enein, A.A., Labib, M.R., Aboul-Gheit, A.K., 2013. Direct Conversion of Natural Gas into COx-free Hydrogen and MWCNTs over Commercial Ni$\mathrm{Mo} / \mathrm{Al}_{2} \mathrm{O}_{3}$ Catalyst: Effect of Reaction Parameters. Egyptian Journal of Petroleum, Volume 22(1), pp. 27-34

Dupuis, A., 2005. The Catalyst in the CCVD of Carbon Nanotubes-A Review. Progress in Materials Science, Volume 50(8), pp. 929-961

Fonseca, A., Hernadi, K., Nagya, B., Bernaerts, D., Lucas, A.A., 1996. Optimization of Catalytic Production and Purification of Buckytubes. Journal of Molecular Catalysis A: Chemical, Volume 107(1-3), pp. 159-168 
Gangupomu, R.H., Sattler, M.L., Ramirez, D., 2016. Comparative Study of Carbon Nanotubes and Granular Activated Carbon: Physicochemical Properties and Adsorption Capacities. Journal of Hazardous Materials, 302, pp. 362-374

Groen, J.C., Peffer, L.A.A., Perez-Ramırez, J., 2003. Review - Pore Size Determination in Modified Micro- and Mesoporous Materials. Pitfalls and Limitations in Gas Adsorption Data Analysis. Microporous and Mesoporous Materials, Volume 60(1-3), pp. 1-17

Hernadi, K., Fonseca, A., Nagya, J.B., Siska, A., Kiricsi, I., 2000. Production of Nanotubes by the Catalytic Decomposition of Different Carbon-containing Compounds. Applied Catalysis A: General, Volume 199(2), pp. 245-255

Hordy, N., Mendoza-Gonzalez, N., Coulombe, S., Meunier, J., 2013. The Effect of Carbon Input on the Morphology and Attachment of Carbon Nanotubes Grown Directly from Stainless Steel. Carbon, Volume 63, pp. 348-357

Hsieh, C., Lin, Y., Lin, J., Wei, J., 2009. Synthesis of Carbon Nanotubes over Ni- and Cosupported $\mathrm{CaCO}_{3}$ Catalysts using Catalytic Chemical Vapor Deposition. Materials Chemistry and Physics, Volume 114(2-3), pp. 702-708

Huang, J., Zhang, Q., Wei, F., Qian, W., Wang, D., Hu, L., 2008. Liquefied Petroleum Gas Containing Sulfur as the Carbon Source for Carbon Nanotube Forests. Carbon, Volume 46(2), pp. 291-296

Kuo, C.Y., Wu, C.H., Wu, J.Y., 2008. Adsorption of Direct Dyes from Aqueous Solutions by Carbon Nanotubes: Determination of Equilibrium, Kinetics and Thermodynamics Parameters. Journal of Colloid and Interface Science, Volume 327(2), pp. 308-315

Lee, S.Y., Park, S.J., 2012. Influence of the Pore Size in Multi-walled Carbon Nanotubes on the Hydrogen Storage Behaviors. Journal of Solid State Chemistry, Volume 194, pp. 307-312

Liu, Q., Fang, Y., 2006. New Technique of Synthesizing Single-walled Carbon Nanotubes from Ethanol using Fluidized-bed over $\mathrm{Fe}-\mathrm{Mo} / \mathrm{MgO}$ Catalyst. Spectrochimica Acta Part A, Volume 64(2), pp. 296-300

Maccalini, E., Tsoufis, T., Policicchio, A., Rosa, S.L., Caruso, T., Chiarello, G., Colavita, E., Formoso, V., Gournis, D., Agostino, R.G., 2010. A Spectro-microscopic Investigation of FeCo Bimetallic Catalysts Supported on $\mathrm{MgO}$ for the Production of Thin Carbon Nanotubes. Carbon, Volume 48(12), pp. 3434-3445

Ni, L., Kuroda, K., Zhou, L., Kizuka, T., Ohta, K., Matsuishi, K., Nakamura, J., 2006. Kinetic Study of Carbon Nanotube Synthesis over Mo/Co/MgO Catalysts. Carbon, Volume 44(11), pp. 2265-2272

Ni, L., Kuroda, K., Zhou, L., Ohta, K., Matsuishi, K., Nakamura, J., 2009. Decomposition of Metal Carbides as an Elementary Step of Carbon Nanotube Synthesis. Carbon, Volume 47(13), pp. 3054-3062

Reyhani, A., Mortazavi, S.Z., Akhavan, O., Moshfegh, A.Z., Lahooti, S., 2007. Effect of Ni, Pd and Ni-Pd Nano-islands on Morphology and Structure of Multi-wall Carbon Nanotubes. Applied Surface Science, Volume 253(20), pp. 8458-8462

Tapasztó, L., Kertész, K., Vértesy, Z., Horváth, Z.E., Koós, A.A., Osváth, Z., Sárközi, Z., Darabont, A., Biró, L.P., 2005. Diameter and Morphology Dependence on Experimental Conditions of Carbon Nanotube Arrays Grown by Spray Pyrolysis. Carbon, Volume 43(5), pp. 970-977

Tsoufis, T., Xidas, P., Jankovic, L., Gournis, D., Saranti, A., Bakas, T., Karakassides, M.A. 2007. Catalytic Production of Carbon Nanotubes over Fe-Ni Bimetallic Catalysts Supported on MgO. Diamond \& Related Materials, Volume 16(1), pp. 155-160

Wang, G., Wang, J., Wang, H., Bai, J., 2014. Preparation and Evaluation of Molybdenum Modified Fe/MgO Catalysts for the Production of Single-walled Carbon Nanotubes and Hydrogen-rich Gas by Ethanol Decomposition. Journal of Environmental Chemical Engineering, Volume 2(3), pp. 1588-1595 
Wang, Z.M., Hoshinoo, K., Yamagishi, M. Yoshizawa, N., Kanoh, H., Hirotsu, T., 2006. Formation of Graphite-derived Layered Mesoporous Carbon Materials. Microporous and Mesoporous Materials, Volume 93(1-3), pp. 254-262

Wei, F., Zhang, Q., Qian, W., Yu, H., Wang, Y., Luo, G., Xu, G., Wang, D., 2008. The Mass Production of Carbon Nanotubes using a Nano-agglomerate Fluidized Bed Reactor: A Multiscale Space-time Analysis. Powder Technology, Volume 183(1), pp. 10-20

Xu, J., Ibrahim, A., Hu, X., Hong, Y., Su, Y., Wang, H., Li, J., 2016. Preparation of Large Pore Volume $\gamma$-Alumina and Its Performance as Catalyst Support in Phenol Hydroxylation. Microporous and Mesoporous Materials, Volume 231, pp. 1-8

Zhang, Q., Huang, J., Zhao, M., Qian, W., Wei, F., 2011. Carbon Nanotube Mass Production: Principles and Processes. ChemSusChem, Volume 4(7), pp. 864-889 